\title{
THYROID FUNCTION TESTS IN NIGERIAN HIV SERO- POSITIVE PATIENTS ON HIGHLY ACTIVE ANTIRETROVIRAL THERAPY (HAART)
}

\author{
ABBIYESUKU F.M. ${ }^{1}$, OSUJI K.C. ${ }^{*}$, KUTI M.0. ${ }^{1}$ AND ATIBA A.S. ${ }^{3}$ \\ ${ }^{1}$ Department of Chemical Pathology, Faculty of Basic Medical Sciences, College of Medicine, University of Ibadan, Oyo State, Nigeria. \\ 2Department of Chemical Pathology, Irrua Specialist Teaching Hospital, Irrua, Edo State, Nigeria. \\ 3Department of Chemical Pathology, Ekiti State University, Ado-Ekiti, Nigeria. \\ *Corresponding Author: Email- iji70@hotmail.com
}

Received: February 21, 2014; Accepted: March 27, 2014

\begin{abstract}
Background: Recent studies suggest that the prevalence of hypothyroidism among human immunodeficiency virus (HIV) people who were on treatment with highly active antiretroviral therapy (HAART) was higher than that in treatment naïve HIV infected people and those who were not infected with HIV.
\end{abstract}

Objective: This study was to determine thyroid function test in HIV infected people on various regimen of HAART.

Subjects and Methods: A total of 128 participants were randomly recruited for the study. Seventy six were HIV positive on HAART, 24 were HIV positive but treatment-naïve and HIV negative population was 28. Blood samples were collected from each study group for thyroid stimulating hormone $(\mathrm{TSH})$, free thyroxine $\left(\mathrm{FT}_{4}\right)$ and free triiodothyronine $\left(\mathrm{FT}_{3}\right)$. A chemiluminescence based third generation thyroid assay was used for the analysis of these parameters.

Result. Free T3 and fT4 were observed to be significantly lower in HIV positive patients whether on HEART or not than those that were HIVnegative $(p>0.001$ and $p=0.014)$. Correspondingly, TSH was found to be significantly higher in test groups than normal HIV-negative control, $p<0.001$.

Conclussion: There is no difference in thyroid function test among HIV infected people, whether treatment naïve or on HAART. However, thyroid hormones (fT3, fT4) was lower in HIV positive patients than HIV-negative controls.

Keywords- Thyroid function test, Human immunodeficiency virus (HIV), free T4, free T3, Thyroid Stimulating Hormone

Citation: Abbiyesuku F.M., et al. (2014) Thyroid Function Tests in Nigerian HIV Sero- Positive Patients on Highly Active Antiretroviral Therapy (HAART). International Journal of Medical and Clinical Research, ISSN: 0976-5530 \& E-ISSN: 0976-5549, Volume 5, Issue 1, pp.-277-281.

Copyright: Copyright@2014 Abbiyesuku F.M., et al. This is an open-access article distributed under the terms of the Creative Commons Attribution License, which permits unrestricted use, distribution and reproduction in any medium, provided the original author and source are credited.

\section{Introduction}

Cases of clinical and subclinical endocrine dysfunctions, in association with other metabolic derangements had been described in HIV positive patients even before the advent of highly active antiretroviral therapy (HAART) [1-4]. Commonly reported endocrine dysfunctions then were gonadal, adrenal and thyroid dysfunctions while other metabolic abnormalities involved fat distribution (lipodystrophy) nutrition and renal functions [1-4]. Opportunistic infections, neoplastic infiltration as well as HIV viraemia have been implicated [1-3].

With the advent of HAART, there has been a significant improvement in the prognosis of HIV infection, but this has been at a cost. However, there are numerous adverse effects of the individual drugs and combinations used in HAART [5-8]. Usually two nucleoside reverse transcriptase inhibitors (NRTIs) are combined with either a non nucleoside reverse transcriptase inhibitor (NNRTI) or a protease inhibitor (P1) $[5,6,9]$. Among other adverse reactions of
HAART is now thyroid dysfunctions which has been recently described. $[7,10,11,12]$.

Thyroid dysfunctions secondary to HAART therapy of HIV infection can be classified into overt and subclinical hyperthyroidism and overt and subclinical hypothyroidism [7,11]. Overt hyperthyroidism is defined as elevated serum free triiodothyronine $\left(\mathrm{FT}_{3}\right)$ and free thyroxine $\left(\mathrm{FT}_{4}\right)$ levels in the presence of a very low to undetectable serum TSH value. Subclinical hyperthyroidism is defined as a normal $\mathrm{fT}_{3}$ and $\mathrm{fT}_{4}$ in the presence of a low TSH value. Overt hypothyroidism is defined as elevated serum TSH value while subclinical hypothyroidism is defined as normal $\mathrm{fT}_{3}$ and $\mathrm{fT}_{4}$ in the presence of an elevated serum TSH [7].

While some authors agree that clinical thyroid disease is relatively rare in stable HIV positive patients who are not on treatment especially early in the course of the disease. Others have reported fine needle aspiration cytology (FNAC), histology and autopsy findings of thyroiditis secondary to viral and opportunistic infections and 
neoplastic infiltration of the gland, producing features of both hyperthyroidism and hypothyroidism [1].

Several studies carried out in different centres over the last few years have all suggested that there is an increased prevalence of thyroid dysfunctions among HIV positive people on treatment with HAART. This could be self-explained considering the additive effect one expects on thyroid function from both HIV effects and the adverse effects of HAART. The reports of Beltran et al [7] in 2003 in France established a significant relationship between an increased risk of developing hypothyroidism among their patients placed on nucleoside analogue, stavudine. They suggested that all HIV Infected patients on HAART should be routinely screened for thyroid dysfunctions. This view however, is still controversial $[13,14]$.

With the advent of programmes offering antiretroviral drugs to HIV infected people in this environment at highly subsidized rates, it has become imperative to determine if HAART will predispose Nigerian HIVIAIDS patients to a higher risk of hypothyroidism and if routine screening for thyroid dysfunctions among these patients is required. This is bearing in mind, that the presence of an untreated thyroid dysfunction in HIV infected patients will worsen their prognosis, especially when thyroid dysfunctions are easily treatable.

\section{Subjects, Materials and Methods \\ Study Design}

Cross-sectional retrospective single centred study.

\section{Recruitment of Patients/Samples}

A total of 128 people were recruited into the study. Seventy six of them were HIV positive patients selected randomly from the population of patients attending the Presidential Emergency Programme for AIDS Relief (PEPFAR) and AIDS Prevention Initiative in Nigeria (APIN) clinic, at the University College Hospital (UCH) Ibadan who had been on HAART for a minimum period of six months. This sample size was approximated from calculated sample size of 64.63 using HIV prevalence rate of $4.4 \%$ and desired precision limit taken to be $5 \%$. Twenty four other patients who had HIV infection, but were not on antiretroviral therapy were selected randomly and matched for age and sex from the same clinic to form a control group. Another control group termed the control-normal group, composed of 28 people was selected randomly from the population of medical and non medical staff of the University College Hospital, Ibadan, they were free of thyroid and non thyroidal illnesses. All selected groups were not known to have pre-existing thyroid abnormalities or be on any medication that will affect thyroid function. Pregnant women were excluded from the study. People selected for the study were then sampled with a data collection form, had their blood pressure, height and weight measurements taken before $3 \mathrm{mls}$ of venous blood was taken from their ante-cubital vein after routine aseptic procedure of venepuncture, into a lithium/heparin specimen bottle. Samples were spun and separated within 3 hours of collection and stored at $-20^{\circ} \mathrm{C}$ until analysis for $\mathrm{fT}_{3}, \mathrm{fT}_{4}$ and $\mathrm{TSH}$, with the oldest sample in storage being less than two months. $C D_{4}$ count and viral RNA load was also done for all the patients in the test group and control-HIV group. Thyroid function test (TFT) was carried out using the Access ${ }^{R}$ immunoassay system manufactured by Beckman Coulter TM. CD4 cell count was done by flow cytometry (Becton-Dickinson, Rutherfort, New Jersey, USA) and viral RNA load was by reverse transcriptase polymerase chain reaction (RTPCR).

\section{Statistical Analysis}

Data were reported as mean $( \pm S D)$. Significance testing was done using either Student's t-test, or Chi-square as appropriate. Associateion of variables within the study groups were done using analysis of variant (ANOVA). Level of significance was set at $p=5 \%$.

\section{Results}

[Table-1] shows demographic and clinical data distribution among the studied groups. The age distribution were similar $(p=0.388)$. There was no also significant difference $p=0.322,0.450$ and 0.252 respectively) in height, weight and BMl among the study groups. Systemic diastolic blood pressure was found to be significantly $(p<0.001)$ higher in control HIV negative group than other study groups. However, the mean value got from this HIV negative group was within acceptable limits.

Our subjects on HAART were found to be placed on one combination involved any of the following drugs: Stavudine, Abacavir, Zidovudine, Didanosine, Emtricitabine, Tenofovir, Efavirenz, Indinavir, Retonavir, Lamivudine, Stavudine.

Comparison of laboratory parameters was done and as shown in [Table-2]. There was significantly $(p<0.001)$ lower CD4 count in HIV positive on HAART than those without HAART. Viral load was found to be higher in patient on HAART than those without HAART $p=0.364$. Free $T 3$ and $\mathrm{fT} 4$ were observed to be significantly lower in HIV positive patients whether on HAART or not than those that were HIV-negative $(p>0.001$ and $p=0.014)$, this is also shown in [Table-3]. Correspondingly, TSH was found to be significantly higher in test groups than normal HIV-negative control, $p<0.001$.

\begin{tabular}{|lccccc|}
\hline \multicolumn{5}{c}{ Table 1- Demographic and Clinical Data Distribution } \\
\hline N & Total & HIV-P1 & HIV-P2 & CN & P-Value \\
Age (yrs) & 128 & 76 & 24 & 28 & \\
& 37.28 & 38.05 & 36.00 & 36.29 & 0.388 \\
Height (cm) & $(7.67)$ & $(7.97)$ & $(6.065)$ & $(8.07)$ & \\
& 162.3 & 161.99 & 164.60 & - & 0.322 \\
Weight (kg) & $(7.78)$ & $(8.03)$ & $(5.46)$ & & \\
& 57.87 & 56.63 & 66.32 & - & 0.45 \\
BMI & $(15.04)$ & $(14.96)$ & $(13.32)$ & & \\
& & 21.40 & 23.34 & - & 0.252 \\
Syst. BP (mmHg) & 111.83 & 105.53 & 108.18 & 130.14 & \\
& $(17.86)$ & $(16.08)$ & $(17.21)$ & $(7.3)$ & $<0.001$ \\
Diast. BP (mmHg) & 69.46 & 68.52 & 69.09 & 72.14 & \multirow{2}{*}{0.324} \\
& $(10.66)$ & $(12 / 43)$ & $(8.31)$ & $(6.02)$ & \\
\hline
\end{tabular}

HIV- P1: HIV-positive on HAART; HIV- P2: HIV-positive treatment naïve; $\mathrm{CN}$ : Control-Normal

Table 2- Comparison of Laboratory Data among the Study Groups

\begin{tabular}{|lccccc|} 
& Total & HIV-P1 & HIV-P2 & CN & P-Value \\
\hline $\mathrm{CD}_{4}$ (cells/ml) & 227.53 & 187.95 & 442.43 & & $<0.001$ \\
& $(194.15)$ & $(162.53)$ & $(216.28)$ & - & \\
Viral RNA Load & $4.91 \times 10^{5}$ & $5.59 \times 10^{5}$ & $1.62 \times 10^{5}$ & & 0.364 \\
(copies/ml) & $\left(1.48 \times 10^{6}\right)$ & $\left(1.6 \times 10^{6}\right)$ & $\left(4.1 \times 10^{5}\right)$ & - & \\
& 4.45 & 4.38 & 4.24 & 4.83 & 0.001 \\
$\mathrm{fT}_{3}$ (pmol/L) & $(0.61)$ & $(0.60)$ & $(0.54)$ & $(0.53)$ & \\
& 9.96 & 9.73 & 9.29 & 11.12 & 0.014 \\
$\mathrm{fT}_{4}$ (pmol/L) & $(2.49)$ & $(2.65)$ & $(2.11)$ & $(1.98)$ & \\
& 1.57 & 1.84 & 1.2 & 1.09 & $<0.001$ \\
$\mathrm{TSH}$ (mlU/L & $(0.91)$ & $(0.96)$ & $(0.78)$ & $(0.57)$ & \\
& & &
\end{tabular}

HIV- P1: HIV-positive on HAART; HIV- P2: HIV-positive treatment naïve; $\mathrm{CN}$ : Control-Normal 


\section{Discussion}

The lower fT3, fT4 and the corresponding higher TSH observed more in HIV-positive group on HAART could be as result of additive effect of HIV infection itself and various components of HAART on thyroid function. Prior to HAART there was little or no evidence of a uniform pattern of association between thyroid dysfunctions and HIV infection [15]. However recent studies suggest an increased prevalence of thyroid dysfunctions since the advent of HAART $[7,13,16]$. These data from Europe were obtained in various sub populations with differing background prevalence of thyroid dysfunctions [15].

Studies of the prevalence of thyroid abnormalities among blacks suggest that blacks tend to have lower prevalence of thyroid dysfunctions [17,18]. Sichieri $R$ et al, [17] in 2007 studied the prevalence of hypothyroidism among three different races resident in Rio de Janeiro, Brazil and reported that while the overall prevalence of hypothyroidism among the whites was $16.7 \%$, it was $8.8 \%$ among mulattos and $6.9 \%$ among blacks. Also Kanaya $A$ M et al, [18] in 2002 reported that blacks in San Francisco California had a lower prevalence of thyroid dysfunctions compared with whites in the same locality. Both studies looked at people from the general population of residents in their respective localities without regards to their HIV status. They further suggest strongly that the background prevalence of thyroid abnormalities in the environment in which this study was carried out is likely to be lower than that of the environments in which the studies in Europe were carried out.

Beltran et al [7] studied 350 HIV infected people on HAART for a mean period of 9.4years (SD 4.9), in France, a country in Europe. Their study population had men in the majority (67\%) (236 men and 114 women) and they were largely immunocompetent with the mean $\mathrm{CD}_{4}$ count at 383.8 cells/ml (SD 288.2). They found a total prevalence of $16 \%$ for hypothyroidism, which they further broke down to $2.6 \%$ for overt hypothyroidism, $6.6 \%$ for subclinical hypothyroidism and $6.8 \%$ for isolated low $\mathrm{fT}_{4}$ levels. These prevalence values were compared to the prevalence in the general population and found to be high. Furthermore Sen $P$ et al [19] and Billaud E [20] studied patients who had mean $\mathrm{CD}_{4}$ counts of $228 \mathrm{cells} / \mathrm{ml}$ and $457 \mathrm{cell} / \mathrm{s} / \mathrm{ml}$ respectively, also the patients in the two groups had been on HAART for mean periods of 7years and 4years respectively, thereby differing from the test population in this study who were all Nigerians, and were largely immunocompromised with a mean $\mathrm{CD}_{4}$ count of 187 cells $/ \mathrm{ml}$ (SD 162) and viral RNA load of $5.59 \times 10^{5}$ (SD $1.6 \times 10^{6}$ ) despite being on HAART. This may be due to the fact that HAART for HIV is a relatively new innovation in Nigeria, having only started on a small scale in 2004, with the implication that most of the patients studied were on HAART for shorter periods than those in the Beltran [7], Sen P [16] and Billaud E [20], studies. Thus the study populations of the studies cited above are significantly different from those used in this study and this may have accounted for the difference in our findings.

The isolated low $\mathrm{fT}_{4}$ finding [Table-3] is obviously significant and is in agreement with the findings by Beltran et al [7], who reported a similar prevalence of $6.6 \%$ among their own patients and Billaud $\mathrm{E}$, [20] who reported a prevalence of $4 \%$ isolated low $\mathrm{fT}_{4}$ among the 221 patients he studied in France in 2001, his patients were like Beltran group's mostly men who had been on HAART for a mean period of 50 months, they were largely immunocompetent with mean CD4 counts and viral RNA load of 457 cells $/ \mathrm{ml}$ and 1,000 copies/ml respectively.
Also the prevalence of isolated low $\mathrm{FT}_{4}$ among the test population in this study is in agreement with that of Ketsamathi $C$ et al, [21] who in 2006 reported a similar prevalence of $6 \%$ among 200 HIVinfected Thai patients who were on HAART, their patients were mostly young people (mean age 36.3yrs) (SD 8.3), and immunocompetent (mean $\mathrm{CD}_{4}$ count 340.6 cells/ml) (SD 175.1). However in variance to this study Beltran et al [7], Billaud E [20] and Ketsamathi $C$ et al [21] all found various prevalence of overt and subclinical hypothyroidism among their study populations.

This study also found a similarly high prevalence of $8.3 \%$ for low $\mathrm{fT}_{3}$ and $\mathrm{fT}_{4}$ in the presence of a normal TSH value and $12.5 \%$ each for isolated low $\mathrm{fT}_{3}$ and $\mathrm{fT}_{4}$ respectively among the control-HIV group (i.e. HIV infected people who were not on HAART, [Table-3] a finding which is in agreement with that by Bongiovani et al, [22] and Quirino et al [23]. In their study in Italy in 2006, Bongiovani and his group studied a total of 190 HIV infected subjects who they classified three groups, $G_{1}, G_{2}$ and $G_{3}$. The $G_{1}$ subjects were those on stable HAART for a minimum period of one year, the $G_{2}$ were those who were antiretroviral treatment naïve, while the $\mathrm{G}_{3}$ subjects were people just starting HAART. At baseline they found a $14.4 \%$ prevalence of subclinical hypothyroidism in the $\mathrm{G}_{1}$ group, $10.6 \%$ in the $\mathrm{G}_{2}$ group and $8.7 \%$ in the $\mathrm{G}_{3}$ group. They actually suggested that the prevalence of thyroid abnormalities in HIV infected people was similar irrespective of HAART. When compared with the control-normal group, in which a prevalence of $0 \%$ was recorded for isolated low $\mathrm{fT}_{3}$ and $3.6 \%$ for isolated low $\mathrm{fT}_{4}$. These findings suggest that HIV infection on it's own, has a role to play in the causation of thyroid abnormalities and as has been elucidated earlier in the literature review, background clinical and subclinical opportunistic infections are likely to be implicated in these group of patients, especially those in this study who are largely immunocompromised.

Two subjects had subclinical hyperthyroidism, one each in the test and control-normal groups respectively, this finding is important when compared with the Beltran study which found two cases of subclinical hyperthyroidism. Billaud E [20] and Kitsamathi C et al [21] also reported that two people each had hyperthyroidism in their study populations.

One case each of elevated $\mathrm{fT}_{3}$ and $\mathrm{fT}_{4}$ were found in two members of the test group who were both on nevirapine an NNRTI.

The finding of isolated low $\mathrm{fT}_{3}$ in a significant percentage of the test and control-HIV groups is explained by the sick euthyroid syndrome, which is usually characterized by reduced $\mathrm{fT}_{3}$ levels, elevated $\mathrm{RT}_{3}$ levels, variable $\mathrm{fT}_{4}$ levels and relatively normal or decreased TSH levels depending on the severity of illness. It is said to be common in HIV infection, especially with progression of disease [24,25]. With a mean CD4 count of 227.5 cells/ml (SD 194.15) and a mean viral RNA load of $4.01 \times 10^{5}$ copies/ml (SD $1.48 \times 10^{6}$ ) in these groups of patients, it is obvious that majority of them are largely immunocompromised.

Low $\mathrm{fT}_{4}$ levels with concurrent normal TSH levels as found in this study $(7.9 \%$ and $12.5 \%$ for the test population and control-HIV groups respectively), are frequently seen among HIV infected individuals with reported prevalence of between $1.3 \%$ - 17\% $[7,13,26]$. This was initially thought to be due to pituitary or hypothalamic failure, but in one study, administration of exogenous thyrotropin releasing hormone (TRH) neither caused delayed or absent TSH response in these patients thus making, neither hypothalamic nor pituitary insufficiency a likely cause of the low $\mathrm{fT}_{4}$ in HIV patients [27]. Another study found decreased $\mathrm{fT}_{4}$ levels in asymptomatic HIV 
infected patients, who had greater mean 24 hours TSH levels and a higher mean TSH peak after TRH stimulation than control subjects. This suggests an intact but hypothyroid like regulation of the pituitary-thyroid axis, thus the finding of isolated low $\mathrm{fT}_{4}$ levels in some patients and combined low $\mathrm{fT}_{3}$ and $\mathrm{fT}_{4}$ levels in the presence of a normal TSH level in some others. Also the possibility of some HAART agents interfering with the assay of $\mathrm{fT}_{4}$ has been suggested [25].

Beltran et al, [7] Madeddu et al, [13] and Billaud E et al [20] associated stavudine, lamivudine and didanosine with the high prevalence of subclinical hypothyroidism, but this study, did not establish a significant relationship between the cases of low $\mathrm{FT}_{3}$ and $\mathrm{FT}_{4}$ and the use of stavudine and lamivudine.

Table 3- Abnormalities of Thyroid Function among the Different Study Groups

\begin{tabular}{|lcccc|} 
& $\begin{array}{c}\text { Low } \mathrm{fT}_{3}, \mathrm{fT}_{4} \text { With } \\
\text { Normal TSH }\end{array}$ & $\begin{array}{c}\text { Isolated } \\
\text { Low } \mathrm{fT}_{3}\end{array}$ & $\begin{array}{c}\text { Isolated } \\
\text { Low } \mathrm{fT}_{4}\end{array}$ & $\begin{array}{c}\text { Subclinical } \\
\text { Hyperthyroidism }\end{array}$ \\
\hline Test Group & $5(66 \%)$ & $6(7.9 \%)$ & $6(7.9 \%)$ & $1(1.3)$ \\
Control-HIV Group & $2(8.3 \%)$ & $3(12.5 \%)$ & $3(12.5 \%)$ & - \\
Control-Normal Group & $2(8.3 \%)$ & $3(12.5 \%)$ & $3(12.5 \%)$ & $1(3.6 \%)$ \\
\hline
\end{tabular}

\section{Conclusion and Recommendation}

This study thus concludes that, there is no difference in thyroid function test among HIV infected people, whether treatment naïve or on HAART. However, thyroid hormones $\left(\mathrm{fT}_{3}, \mathrm{fT}_{4}\right)$ was lower in HIV positive patients than HIV-negative controls.

The patients who had deranged thyroid hormone values should be followed up and thyroid function tests done at least once yearly so that subclinical or overt disease will be detected early, with view to offering them early intervention if necessary.

\section{Acknowledgements}

We thank Drs O M Akinosun and K S Adedapo and all the Resident Doctors in the Department of Chemical Pathology, University College Hospital (UCH) Ibadan. Nigeria, for their contributions to the success of this study. We also acknowledge the contribution of Physicians and staff of the Presidential Emergency Programme for AIDs Relief (PEPFAR) and AIDS Prevention Initiative in Nigeria (APIN) clinic at the UCH Ibadan.

Conflicts of Interest: None of the authors has potential conflicts of interest.

\section{References}

[1] Sellmeyer D. E. and Grunfeld C. (1996) Endocrine Reviews, 17 (5), 518-532.

[2] Carta S., Olivieri M., Sorcini M., Medda E., Fazzini E., Battisti P., Sorcini I. and Grandolfo M. E. (1993) Annali dell'Istituto superiore di sanita, 29(3), 451-456.

[3] Mulligan K. \& Schambelan M. (2003) HIV-Associated wasting, HIV in Site knowledge Base Chapter.

[4] Hinz S., McCormack D. and Van der Spuy Z.M. (2002) Gynecological endocrinology, 16(1), 33-38.

[5] Montessori V., Press N., Harris M., Akagi L. and Montaner J.S.G. (2004) Canadian Medical Association Journal, 170(2), 229-238.

[6] Badri M., Maartens G., Mandalia S., Bekker L.G., Penrod J.R.,
Platt R.W., Wood R. and Beck J.B. (2005) PLOS Medicine, 3 (1), e4.

[7] Beltran S., Lescure F., Desaillound R., Donadi Y., Smail A., El Esper I., Arlot S. and Schmit J.L. (2003) Clinical infectious diseases, 37(4), 579-583.

[8] Palella F.J., Delaney K.M., Moorman A.C., Loveless M.O., Fuhrer J., Satten G.A., Aschman D.J. and Holmberg S.D. (1998) New England Journal of Medicine, 338(13), 853-860.

[9] Bassetti S., Battegay M., Furrer H., Rickenbach M., Flepp M., Kaiser L., Telenti A., Vernezza P.L., Bernasconi E. and Sundre P. (1999) Journal of Acquired Immune Deficiency Syndromes, 21(2), 114-119.

[10]Chow D.C., Day L.J., Souza S.A. and Shikuma C.M. (2006) Metabolic complication of HIV therapy, HIV InSite Knowledge Base Chapter, 1-27.

[11]Merenich J.A., McDermott M.T., ASP A.A., Harrison S.M. and Kid G.S. (1990) The Journal of Clinical Endocrinology \& Metabolism, 70(3), 566-571.

[12]Vigano A., Riboni S., Bianchi R., Cafarelli L., Vago T., Manzoni P.N. and Di Natale B. (2004) The Pediatric Infectious Disease Journal, 23(3), 235-239.

[13]Madeddu G., Spanu A., Chesa F., Calia G.M., Lovigu C., Solinas P., Mannazzu M., Falchi A., Mura M.S. and Madeddu G. (2006) Clinical Endocrinology, 64(4), 375-83.

[14]Kotegoda R., Madge S., Smith C.J., Lampe F.C., Thomas M. and Harvey R. (2005) No association between HIV disease and its treatment and thyroid function, 55th Meeting of the British Thyroid Association, London.

[15]Madge S., Smith C.J., Lampe F.C., Thomas M., Johnson M.A., Youle M. and Vanderpump M. (2007) HIV Medicine, 8(1), 2227.

[16]Sen P., Scourfield A., Smythe J., Stefanovich M., Jones R., Mandalia S., Sullivan A.K., Nelson M.R. and Gazzard B.G. (2005) Thyroid dysfunction in individuals with HIV Infections: The effect of HAART, The International AIDS Conference, Rio de Janeiro, Brazil.

[17]Sichieri R., Baima J., Marante T., De Vasconcellos M.T.L., Moura A.S. and Vaisman M. (2007) Clinical Endocrinology, 66 (6), 803-807.

[18]Kanaya A.M., Harris F., Volpato S., Pérez-Stable E.J., Harris T. and Bauer D.C. (2002) Archives of Internal Medicine, 162(7), 773-779.

[19]Benseñor I. (2002) São Paulo medical journal, 120(5), 146-151.

[20]Billaud E. (2001) High prevalence of thyroid abnormality in the era of HAART, The 3rd International workshop on Adverse drug reactions and lipodystrophy in HIV, Athens, Greece.

[21]Ketsamathi C., Jongjaroenprasert W., Chailurkit L.O., Udomsubpayakul U. and Kiertiburanakul S. (2006) Current HIV Research, 4(4), 463-467.

[22]Bongiovani M., Adorni F., Casana M., Tordato F., Tincartic C., Cicconi P., Bini T. and d'Arminio Monforte A. (2006) Journal of Antimicrobial Chemotherapy, 58(5), 1086-1089.

[23]Quirino T., Bongiovani M., Ricci E., Chebat E., Carrodori S., Martinelli C., Valsecchi L., Landonio S., Bini T. and Bonfanti P. (2004) Clinical Infectious Diseases, 38(4), 596-597. 
[24]Jameson J.L., Weetman A.P. (2001) Harrison's Principles of Internal Medicine, 16th ed., 2060-2083.

[25]Mayer K.H., Hoffmann C.J. and Brown T.T. (2007) Clinical Infectious Diseases, 45(4), 488-494.

[26]Chen F., Day S.L., Metcalf R.A., Sethi G., Kapembwa M.S., Brook M.G., Churchill D., de Ruiter A., Robinson S., Lacey C.J. and Weetman A.P. (2005) Medicine, Baltimore, 84(2), 98-106.

[27]Hommes M.J.T., Romijn J.A., Endert E., Andriaanse R., Brabant G., Eeftinck Schattenkerk J.K.M., Wiersinga W.M. and Sauewein H.P. (1993) Metabolism, 42(5), 556-561. 